visible, one between the central spot and the first 'extra' ring and the other between the 200 and the outermost 'extra' ring just inside the 111. 'The first, third and fourth 'extra' rings correspond to diffraction of the primary beam by plane gratings consisting of the atoms in the (111) exit faces, while the second and also the fourth correspond to diffraction by (120) exit planes. As the electron wave-fronts pass down the inclined exit faces, the third Laue condition and the structure amplitude restrictions relax and finally disappear, with the result that one intense band is swept out between the 200 and the fourth 'extra' ring and another between the central spot and the first 'extra' ring. A similar explanation has been found to account for the other bands and 'extra' rings so far observed.

The value of the 'extra' rings and bands in crystal structure analysis is evident. We have here for the first time a possible means for identifying the actual crystal faces in crystals of sub-microscopic dimensions.

G. I. FinCH.

A. G. Quarrell.

Department of Chemical Technology,

Imperial College of Science

and Technology,

S.W.7.

\section{Differences between Male Hormone Extracts from Urine and from Testes}

THE identity of the male hormone, extracted respectively from urine and from testes, has been assumed but never proved since the original isolation

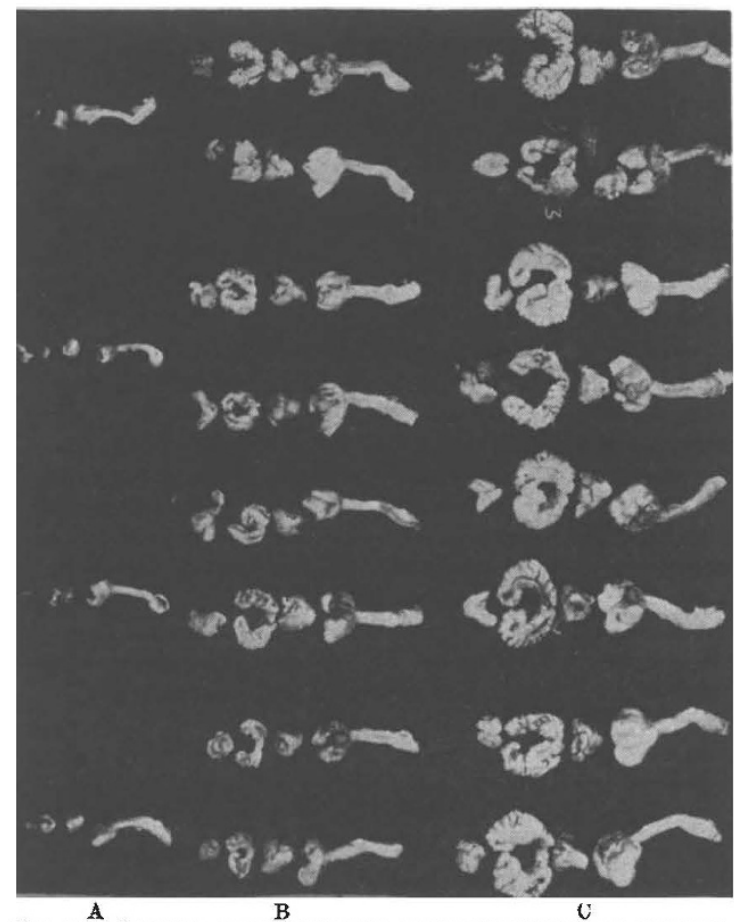

FIG. 1. ${ }^{\text {A }}$ Prostate, seminal vesicles, periurethral tissue and penes of rats : A, controls; B, treated with urinary extract ; C, treated with testis extract.

of active substances from these two sources. We ${ }^{1}$ and also other authors ${ }^{2,3}$ have pointed out various chemical and biological differences. The following experiment shows a more definitive differentiation.
Twenty-one male rats were castrated when 3-31 weeks old ; and at the age of 6-6 $\frac{1}{2}$ months, when the average weight was about $260 \mathrm{gm}$., were divided into three groups. The first group of five animals was untreated. The second group of eight animals received injections of male hormone extracted from urine; the third group of eight animals, injections of male hormone extracted from testicles.

The extracts were administered during four periods of six days, the dosage being increased at each phase. The preparations had been standardised on capons. During the first six days, $2 \times 0.5$ comb units (c.v.) daily were given; during the second six days, $2 \times 1$ c.U.; during the third six days $2 \times 2$ c.U.; and during the fourth six days $2 \times 4$ c.U. When the animals were killed on the day after the last injection, they showed extraordinary differences in the size of the seminal vesicles (Fig. 1). The average weight of the seminal vesicles was $8 \mathrm{mgm}$. in the controls, $113 \mathrm{mgm}$. in the group treated with urinary extract and $538 \mathrm{mgm}$. in the group treated with testicular extract. The difference in size of the prostate of the injected animals was much less (6 mgm., 66 mgm., $105 \mathrm{mgm}$.). The histological findings are to be published later.

\section{E. Dingemanse. \\ J. Freud. \\ E. LAQUEUR.}

Pharmaco-Therapeutisch Laboratorium, Universiteit, Amsterdam. Dec. 24

\footnotetext{
1 Laqueur, C. S., and Münch, Ber. ges. Physiol., 81, 3/4; 1931. Gallagher, T. F., and Koch, F. C., Endocrinology, 18, No. 1, 107 1034.

Matsuzaki, K., Jap. J. Med. Sci., 7, No. 1; 1934

Freud, J., and Laqueur, E., Acta Brevia Neerl., 4, 100; 1934

- Freud, J., Acta Brevia Neerl., 4, 81; 1934.
}

\section{Excretion of Nitrogenous Compounds from the Root Nodules of Leguminous Plants}

THE activities of the nodule, and particularly the excretion of nitrogenous compounds from the nodule into the medium, are largely dependent upon the supply of air to the roots. The quantity of excreted nitrogenous compounds is the greater the larger the culture flask. This fact has been clearly demonstrated by our experiments with sterile cultures of inoculated peas in quartz sand. The results also showed that the rate of excretion is proportionally highest at an early stage of development of the plants when the nodules are still quite young. Hence it can be concluded that the passage of the nitrogen compounds into the sand actually is due to excretion and not to a decomposition of the nodule proteins.

We have previously shown ${ }^{1}$ that nitrogen compounds, found in sand after growth of inoculated leguminous plants under sterile conditions, consist mainly of amino-acids. Since these compounds cannot be breakdown products of nodule proteins it is reasonable to assume that the fixation of nitrogen takes place at the surface of the bacterial cells in the nodule, and that nitrogen compounds thus formed are partly utilised by the host plant and partly diffused into the soil. This view receives additional support from the fact that the proteoclastic action of leguminous bacteria and nodules is very slight.

Excretion of nitrogenous compounds from root nodules is not attributable to a mechanical wounding of the root hairs through sharp-edged sand particles, since the same phenomenon was found to 